\title{
Adhesion to zirconia as a function of primers/silane coupling agents, luting cement types, aging and test methods
}

\author{
Rebholz-Zaribaf, Nasanin ; Ȯzcan, Mutlu
}

\begin{abstract}
This study evaluated the adhesion of resin cements to zirconia with different primers/silane coupling agents using two test methods with and without aging. Zirconia discs (Cercon) $(\mathrm{N}=900, \mathrm{n}=15$ per group) were ground finished to 2000 grit silicone carbide and randomly divided into seven groups: (a) C: No treatment (Control), (b) SG: Signum, (c) CL: Clearfil Ceramic Primer, (d) AP: Alloy Primer, (e) Monobond Plus, (f) ES-R: ESPE-Sil after Rocatec and (g) ES-C: ESPE-Sil after CoJet. Methacrylate (Variolink II-VL) and MDP based (Panavia F2.0-PN) dual-polymerized and self-adhesive resin cements (RelyX Unicem-RX) were adhered and polymerized accordingly. The specimens were further randomly divided into two groups to be tested after (a) 24-h dry storage at $37{ }^{\circ} \mathrm{C}$ and $(\mathrm{b})$ thermocycling $\left(\times 5000,5-55{ }^{\circ} \mathrm{C}\right)$. Macroshear (MSB) and macrotensile bond tests (MTB) were conducted in an universal testing machine (crosshead speed: $1 \mathrm{~mm} / \mathrm{min}$ ) and failure types were analyzed after debonding. Data were analyzed using Univariate analysis and Tukey's tests $(\alpha=0.05)$. Two-parameter Weibull modulus, scale $(\mathrm{m})$ and shape $(0)$ were calculated. While primer/silane $(\mathrm{p}<0.001)$, cement type $(\mathrm{p}<0.001)$ and aging $(p<0.001)$ significantly affected the bond results, test method did not show significant difference $(p=0.237)$. In MSB test, Weilbul moduli were more favorable for MP-VL (4.2) and AP-PN (6) combinations and after aging for MP-VL (4.2) and AP-PN (5.66). In MTB test, after aging, Weilbul moduli were more favorable for AP-PN (5.41). Bond strength results mostly decreased with SG (24-92\%) after aging. Cohesive failures in the cement were more frequent with PN (252) compared to VL (83).
\end{abstract}

DOI: https://doi.org/10.1080/01694243.2016.1259727

Posted at the Zurich Open Repository and Archive, University of Zurich

ZORA URL: https://doi.org/10.5167/uzh-146163

Journal Article

Accepted Version

Originally published at:

Rebholz-Zaribaf, Nasanin; Özcan, Mutlu (2017). Adhesion to zirconia as a function of primers/silane coupling agents, luting cement types, aging and test methods. Journal of Adhesion Science and Technology, 31(13):14081421.

DOI: https://doi.org/10.1080/01694243.2016.1259727 
Adhesion to zirconia as a function of primers/silane coupling agents, luting cement types, aging and test methods

Nasanin Rebholz-Zaribaf, DDS / Mutlu Özcan, DDS, Dr.med.dent., Ph.D

${ }^{a}$ Dentist, Horgen, Switzerland

${ }^{b}$ Professor, University of Zurich, Dental Materials Unit, Center for Dental and Oral Medicine, Clinic for Fixed and Removable Prosthodontics and Dental Materials Science, Zurich, Switzerland

Short title: Adhesion of resin cements to zirconia

Correspondance to: Prof. Dr. med. dent. Mutlu Özcan, University of Zürich, Dental Materials Unit, Center for Dental and Oral Medicine Clinic for Fixed and Removable Prosthodontics and 
Dental Materials Science, Plattenstrasse 11, CH-8032, Zürich, Switzerland. Tel: +41-44-63 45600, Fax: +41-44-63 44305. e-mail: mutluozcan@hotmail.com

Abstract: This study evaluated the adhesion of resin cements to zirconia in conjunction with different primers and silane coupling agents using two test methods with and without aging. Zirconia discs (Cercon) (diameter: $10 \mathrm{~mm}$; height: $2 \mathrm{~mm} ; \mathrm{N}=900, \mathrm{n}=15$ per group) were ground finished to 2000 grit silicone carbide abrasives under water, ultrasonically cleaned in distilled water and randomly divided into 7 groups based on the primers/silanes, namely a) C: No treatment (Control), b) SG: Signum (Hereaus Kulzer), c) CL: Clearfil Ceramic Primer (Kuraray), d) AP: Alloy Primer (Kuraray), e) Monobond Plus (Ivoclar Vivadent), f) ES-R: ESPE-Sil after Rocatec (3M ESPE), g) ES-C: ESPE-Sil after CoJet (3M ESPE). Methacrylate (Variolink II-VL) and MDP based (Panavia F2.0PN) dual-polymerized and self-adhesive resin cements (RelyX Unicem-RX) were adhered to the conditioned surfaces and polymerized accordingly. The specimens were further randomly divided into two groups to be tested after a) $24 \mathrm{~h}$ dry storage at $37^{\circ} \mathrm{C}$ and $b)$ thermocycling $\left(x 5000,5-55^{\circ} \mathrm{C}\right)$. Macroshear (MSB) and macrotensile bond tests (MTB) were conducted in a Universal Testing Machine $(1 \mathrm{~mm} / \mathrm{min})$ and failure types were analyzed after debonding. Data were analyzed using Univariate analysis of variance and Tukey`s, Bonneferroni post-hoc test (alpha=0.05). Two-parameter Weibull modulus, scale $(m)$ and shape $(0)$ were calculated. While primer/silane $(p<0.001)$, cement type $(p<0.001)$ and aging $(p<0.001)$ significantly affected the bond results, test method did not show significant difference $(p=0.237)$. After aging, C groups of PN cement $(9.7 \pm 3.4)$ presented significantly higher mean bond strength results compared to other cements $(0-6.3 \pm 4.3)(p<0.05)$. With all primer/silane types, in dry conditions within VL $(8 \pm 3.9-15.4 \pm 6.2)$ and PN cement groups $(10.2 \pm 1.9-14.1 \pm 2.9)$, no significant difference was noted $(p>0.05)$. After aging, PN showed no significant decrease $(9.2 \pm 4.9$ 
- 14.2 \pm 4.5$)(p>0.05)$ but in VL group, only AP $(13.8 \pm 3.7)$ and MP $(11.1+6.1)$ showed significantly higher results compared to those of other silanes $(1 \pm 0.4-9 \pm 5.5)(p<0.05)$. In MSB test, Weilbul moduli were more favourable for MP-VL (4.2) and AP-PN (6) combinations and after aging for MP-VL (4.2) and AP-PN (5.66). In dry conditions, APVL (15.7 \pm 4.9$)$ and MP-VL $(19.6 \pm 4.7)$ and all silanes $(12.1 \pm 2.3-13.3 \pm 1.6)$ except SG

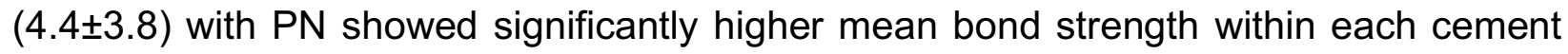
group ( $p<0.05)$. After aging, SG silane with both VL and PN showed significantly lower results $(6 \pm 5,3.3 \pm 2.5$, respectively) $(p<0.05)$. In MTB test, Weilbul moduli were more favourable for MP-VL (4.53) and ES-R-PN (5.59) combinations and after aging for MPVL (4.04) and AP-PN (5.41). In all test and cement combinations, bond strength results decreased the most with SG from 24 to $92 \%$. Cohesive failures in the substrate were not experienced in any of the groups. After aging, cohesive failures in the cement were more frequent with PN (252 out of 450) compared to VL (83 out of 450) with both tests methods.

Keywords: Adhesion; Bond Test; Primer; Resin cements; Silane coupling agent; Surface conditioning; Zirconia 


\section{Introduction}

Ytrium stabilized polycrystalline zirconia (hereafter: zirconia) offers a wide variety of clinical applications, such as full coverage single crowns, fixed-dental-prosthesis (FDPs), resin-bonded FDPs, root posts or implant abutments in reconstructive dentistry. Zirconia has the most favorable properties compared to other high-strength ceramics having flexural strength of 900 to $1200 \mathrm{MPa}$, fracture resistance of more than $2000 \mathrm{~N}$ and fracture toughness of $9-10 \mathrm{MPa} / \mathrm{mm}^{2}$, which is almost twice the value obtained for alumina-based materials and almost three times the value demonstrated by lithium disilicate-based ceramics [1]. With the advances in adhesive promoters, indication of resin-bonded minimal invasive restorations could be considered as an integral part of reconstructive dentistry. In that respect, not only the strength of the restorative material but also the adhesion of resin-based luting cements both to the dental tissues and the particular restorative material is of importance for the long-term clinical success [2,3]. This aspect becomes even more important when retention of FDPs does not rely on macro-mechanical principles as in the case of resin-bonded surface-retained or cantilever FDPs [2,3].

Although etching with hydrofluoric acid and subsequent silanization of the cementation surface of glassy matrix ceramics is an efficient method to achieve durable adhesion of resin-based materials [4,5], neither etching with hydrofluoric or other acids nor applying silane coupling agents resulted in adequate resin bond to zirconia [4,6-10] since such ceramics do not contain a silicon dioxide (silica) phase. For this reason, in order to enhance the adhesion of luting cements to oxide-based ceramics, during the last two decades a number of surface conditioning methods have been suggested [10]. While 
some of these methods facilitate resin-ceramic bonding micro-mechanically employing air-borne particle abrasion with alumina particles $[8,10]$, others are based on physicochemical activation of the ceramic surfaces using silica-coated alumina particles ranging in size from 30 to $250 \mu \mathrm{m}$ followed by silanization $[5,10,11]$ or chemical activation with functional monomer containing cements [10,11]. Among all conditioning methods, particle deposition methods deliver the most favourable adhesion but they may have detrimental effect on the treated zirconia surface creating microcracks, thereby reducing its strength $[12,13]$. Unfortunately, surface roughening of zirconia with air-abrasion methods alone is also not sufficient for adhesion of resin cements [5]. Additional chemical adhesion needs to be achieved using various silane coupling agents, primers and/or luting agents based on phosphate ester monomer 10-methacryloyloxydecyl dihydrogenphosphate (10-MDP), 4-methacryloxyethyl trimellitic anhydride (4-META), thiophosphoric acid methacrylate (MEPS) that can chemically react with oxides on zirconia [14-16]. However, all these cements or adhesion promoters still require airabrasion in order to achieve a clean surface prior to their application according to the manufacturers.

Since the use of conventional resin cements is usually technique sensitive, and each ceramic type requires a different conditioning method, self-adhesive cements were introduced with the aim of simplifying clinical procedures and replacing the sensitive, multi-step procedures during cementation. The material is applied directly on the dentin surface, without any necessity for pre-treatment neither on the dentin, nor on the restorative material surface [17]. When self-adhesive resin cements or etching methods deliver comparable results to air-abrasion methods, possible hazards of particle deposition on zirconia could be eliminated. Likewise, since concerns exist on the 
possible damage created by the air-abrasion methods $[12,13,18,19]$, attempts have been made to promote primers based on organophosphate/carboxylic acid monomers specific for zirconia with which aggressive conditioning methods could be eliminated $[15,20]$. Unfortunately, hydrolytic stability of such primers is still of concern $[14,21,22]$.

Adhesive joints are subjected to both shear and tensile form of forces during chewing. The objectives of this study therefore, were to evaluate the adhesion of dualpolymerized and self-adhesive resin cements to zirconia in conjunction with different primers and silane coupling agents using shear and tensile adhesion test methods with and without aging and to evaluate the failure types after debonding. The null hypotheses tested were that bond strength results would not show significant difference depending on the primer/silane, cement type and aging and the test methods.

\section{Materials and Methods}

Specimen preparation

The brands, chemical compositions, manufacturers and batch numbers of the materials used in this study are listed in Table 1.

Zirconia specimens (N=900) (Cercon, Degudent, Hanau-Wolfgang, Germany) were prepared according to the manufacturer's recommendations (diameter: $10 \mathrm{~mm}$; height: 2 $\mathrm{mm}$ ). The specimens were wet ground finished using silicone carbide papers in sequence $(\# 400,600,800,1200,1500,2000)$ for $30 \mathrm{~s}$ each. After sintering, the specimens were cleaned ultrasonically (Vitasonic, VITA Zahnfabrik, Bad Säckingen, Germany) in distilled water for 10 minutes. Specimens were then embedded in plastic moulds (diameter: $12 \mathrm{~mm}$, height: $10 \mathrm{~mm}$ ) using auto-polymerized polymethylmethacrylate (Scandiquick, Scandia, Hagen, Germany), keeping the upper 
surface free for bonding purposes using a device that maintained the specimens parallel to the x-axis. The specimens were then randomly divided into 7 groups to be conditioned:

Surface conditioning methods

Group C: This group received no primer/silane on the specimen surfaces and acted as the control group.

Group SG: After mixing two components at 1:1 ratio, specimen surfaces were coated with one layer silane based on 10-MDP with acetone solvent (90\%) (Signum Zirconia Bond I+II, Hereaus Kulzer, Hanau, Germany) using a clean brush for every specimen and left to react for $60 \mathrm{~s}$. The specimens were placed in a polymerization unit (Heraflash, HiLite power, Hereaus Kulzer) for $90 \mathrm{~s}$ to accomplish further silane reaction according to the manufacturer`s instructions.

Group CL: Primer and bond were mixed at 1:1 ratio, and specimen surfaces were coated with one layer silane based on 3-methacryloxypropyl trimethoxysilane coupling agent, y-MPS (Clearfil SE Bond with Clearfil Porcelain Bond Activator, Kuraray, Tokyo Japan) with ethanol solvent (80\%) using a clean brush for every specimen, gently airthinned with oil-free air. The surface was then photo-polymerized using an LED unit (Bluephase G2, Ivoclar Vivadent) for $10 \mathrm{~s}$.

Group AP: Specimen surfaces were coated with one layer silane based on 10-MDP and vinyl (Alloy Primer, Kuraray) with acetone solvent (90\%) using a clean brush for every specimen and left to react for 1 minute.

Group MP: Specimen surfaces were coated with one layer silane based on 10-MDP and y-MPS (Monobond Plus, Ivoclar Vivadent, Schaan, Liechtenstein) using a clean brush 
for every specimen and left to react for 1 minute. The surfaces were then gently airthinned with oil-free air.

Group ES-R: In this group, specimen surfaces were initially airborne particle abraded in a laboratory air-abrasion device using tribochemical silica coating system (Rocatec system, 3M ESPE AG, St. Paul, USA). The specimens were first air-abraded with 110 $\mu \mathrm{m} \mathrm{Al}_{2} \mathrm{O}_{3}$ particles (Rocatec-Pre, 3M ESPE) followed by $110 \mu \mathrm{m}$ silica-coated $\mathrm{Al}_{2} \mathrm{O}_{3}$ particles (Rocatec-Plus, 3M ESPE) perpendicular to the surface from a distance of approximately $10 \mathrm{~mm}$ for a period of $15 \mathrm{~s}$ at 2.8 bar pressure. After drying the surface with oil-free air, the conditioned substrates were coated with $\mathrm{y}$-MPS silane with ethanol solvent (90\%) (ESPE-Sil, 3M ESPE) using a clean brush for every specimen and left to react for 1 minute.

Group ES-C: The specimens were air-abraded with $30 \mu \mathrm{m}$ aluminum oxide particles coated with silica (CoJet Sand, 3M ESPE) at 2.8 bar pressure from a distance of approximately $10 \mathrm{~mm}$ from the surface, in a circular motion for $15 \mathrm{~s}$ using an intraoral air-abrasion device (Dento-Prep, RØNVIG, Daugaard, Denmark). After drying the surface with oil-free air, the conditioned substrates were coated with silane as described in group ES-R.

Adhesive procedures

The primed and silanized specimens in each group were further divided into two groups depending on the two dual-polymerized luting cements based on methacrylate (VL, Variolink II, Ivoclar Vivadent) and 10-MDP monomer (PN, Panavia F2.0, Kuraray) to be bonded to the specimens. Separate groups of specimens from Group C received selfadhesive resin cement (RX, RelyX Unicem Aplicap, 3M ESPE) that was activated in the corresponding mixer (Rotomix, 3M ESPE) for $10 \mathrm{~s}$. 
One calibrated operator carried out adhesive procedures throughout the experiments. Translucent polyethylene molds (height: $4 \mathrm{~mm}$, diameter: $3 \mathrm{~mm}$ ) were stabilized on the ceramic specimens in a custom made device. Base and catalyst paste of dual polymerized resin cements were mixed in a 1:1 ratio on a mixing pad for $10 \mathrm{~s}$. The mold was filled with the resin cement, a metal pin was inserted to ensure $100 \mu \mathrm{m}$ cement thickness at the first layer of cement and it was photo-polymerized using an LED unit (Bluephase G2, Ivoclar Vivadent) for $40 \mathrm{~s}$ from 5 directions from a distance of $2 \mathrm{~mm}$. Light intensity was assured to be higher than $1200 \mathrm{~mW} / \mathrm{cm}^{2}$, verified by a radiometer after every 8 specimen (Model 100, Kerr, Orange, CA, USA). Oxygen inhibiting gel (Oxyguard, Kuraray) was applied at the bonded margins and rinsed with cupious water after 1 minute.

Polyethylene molds were gently removed from the test specimens. Half of the specimens were kept dry at $37^{\circ} \mathrm{C}$ for $24 \mathrm{~h}$ in dark and the other half was subjected to thermocycling for 5000 cycles between 5 and $55^{\circ} \mathrm{C}$ in distilled water (Haake DC 10, Thermo Haake, Karlsruhe, Germany). The dwelling time at each temperature was $30 \mathrm{~s}$ and the transfer time from one bath to the other was $10 \mathrm{~s}$.

Macroshear and macrotensile tests

For the macroshear bond test (MSB), specimens were mounted in the jig of the Universal Testing Machine (Zwick ROELL Z2.5 MA 18-1-3/7, Ulm, Germany) and the shear force was applied using a shearing blade to the adhesive interface until failure occurred. The load was applied to the adhesive interface as close as possible to the surface of the substrate at a crosshead speed of $1 \mathrm{~mm} / \mathrm{min}$ and the stress-strain curve was analyzed with the software program (TestXpert, Zwick ROELL, UIm, Germany). For the macrotensile bond test (MTB), specimens were mounted in the corresponding jig 
and resin cement disc was pulled with a grip from the zirconia surface at a crosshead speed of $1 \mathrm{~mm} / \mathrm{min}$.

Microscopic examination and failure analysis

After adhesion tests, debonded specimen surfaces were examined in order to analyze the failure types using an optical microscope (Zeiss MC 80 DX, Jena, Germany) at x50 magnification. Failure types were classified as follows: Score 1: Adhesive failure at ceramic-cement interface with no cement remnants left on the substrate, Score $2:<1 / 3$ cement left adhered on the substrate, Score 3: $>1 / 3$ cement left adhered on the substrate, Score 4: Cohesive failure within the substrate.

Statistical analysis

According to the two-group Satterthwaite t-test (SPSS Software V.20, Chicago, IL, USA) with a 0.05 two-sided significance level, a sample size of 15 in each experimental group was calculated to provide more than $80 \%$ power to detect a difference of $5 \mathrm{MPa}$ between mean values. Kolmogorov-Smirnov and Shapiro-Wilk tests were used to test normal distribution of the data. As the data were normally distributed, Univariate analysis of variance was applied to analyze possible differences between the groups where the bond strength was the dependent variable and primer/silane types ( 7 levels: C, SG, CL, MP, AP, ES-R, ES-C), cement types (3 levels: two dual polymerized and one self adhesive), aging types (2 levels: dry versus thermocycle) and test method (2 levels: macroshear versus macrotensile) as independent variables. Due to significant differences between groups, multiple comparisons were analyzed using Tukey's, Bonneferroni and 2-sided Dunnett-T post hoc tests. Maximum likelihood estimation without a correction factor was used for 2-parameter Weibull distribution to interpret 
predictability and reliability of adhesion (Minitab Software V.16, State College, PA, USA). $P$ values less than 0.05 were considered to be statistically significant in all tests.

\section{Results}

Debonded specimens during thermocycling were considered $0 \mathrm{MPa}$.

While primer/silane $(p<0.001)$, cement type $(p<0.001)$ and aging $(p<0.001)$ significantly affected the bond results, test method did not show significant difference $(p=0.237)$.

With the MSB test, in both dry and aged conditions in non-silanized C groups, VL did not bond on zirconia (0 MPa) (Table 2a). After aging, C groups of PN cement $(9.7 \pm 3.4)$ presented significantly higher mean bond strength results compared to other cements (0 - 6.3 \pm 4.3$)(p<0.05)$. With all primer/silane types, in dry conditions within VL $(8 \pm 3.9$ -

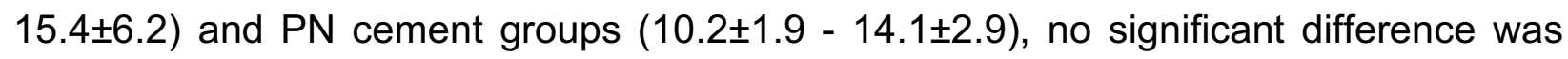
noted $(p>0.05)$. After aging, PN showed no significant decrease $(9.2 \pm 4.9-14.2 \pm 4.5)$ $(p>0.05)$ but in VL, only AP $(13.8 \pm 3.7)$ and MP $(11.1+6.1)$ showed significantly higher results compared to those of other silanes $(1 \pm 0.4-9 \pm 5.5)(p<0.05)$. In MSB test, Weilbul moduli were more favourable for MP-VL (4.2) and AP-PN (6) combinations compared to other groups (2.26-3.03 and 2.5-5.26, for VL and PN, respectively) and after aging for MP-VL (4.2) and AP-PN (5.66).

With the MTB test, in both dry and aged conditions in non-silanized C groups, VL

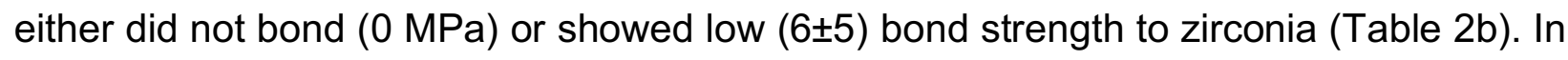

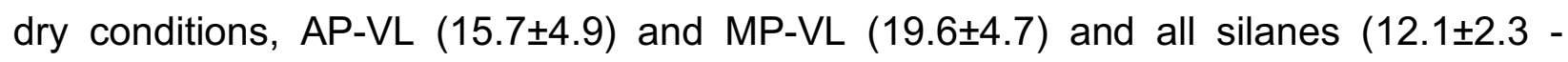
13.3 \pm 1.6$)$ except SG $(4.4 \pm 3.8)$ with PN showed significantly higher mean bond strength within each cement group $(p<0.05)$ (Table $2 b)$. After aging, SG silane with both $V L$ and PN showed significantly lower results $(6 \pm 5,3.3 \pm 2.5$, respectively) $(p<0.05)$. In MTB test, 
Weilbul moduli were more favourable for MP-VL (4.53) and ES-R-PN (5.59) combinations compared to other groups (0.76-3.67 and $0.7-3.89$, for $V L$ and $P N$, respectively) and after aging for MP-VL (4.04) and AP-PN (5.41).

In all test and cement combinations, bond strength results decreased with SG from 24 to $92 \%$ (Figs. 2a-d).

After aging, cohesive failures in the cement were more frequent with PN (252 out of 450) compared to VL (83 out of 450 ) with both tests methods (Tables $2 a-b)$.

\section{Discussion}

For establishing a strong and stable bond of resin-based materials to zirconia has proven to be difficult, as the material is acid resistant and does not respond to common etching and silanization procedures $[4,6,7,10,11]$. This study was undertaken in order to evaluate the adhesion of dual-polymerized and self-adhesive resin cements to zirconia in conjunction with different primers and silane coupling agents under shear and tensile forces before and after aging conditions. Based on the results of this study, except for test methods, since primer/silane, cement type and aging significantly affected the bond results, the null hypotheses tested could be partially rejected.

A number of test methods have been suggested to study adhesion of resin based materials to zirconia (i.e. macroshear, microshear, macrotensile, and microtensile tests). In order to measure the bond strength values between an adherent and a substrate accurately, it is crucial that the bonding interface should be the most stressed region, regardless of the test methodology being employed. Previous studies using stress distribution analyses have reported that some of the bond strength tests do not appropriately stress the interfacial zone $[22,23]$. Shear tests have been criticized for the 
development of non-homogeneous stress distributions at the bonded interface, inducing either underestimation or misinterpretation of the results, as the failure often starts in one of the substrates and not solely at the adhesive zone $[22,23]$. Conventional tensile tests also present some limitations, such as the difficulty of specimen alignment and the tendency for heterogeneous stress distribution at the adhesive interface. On the other hand, when specimens are aligned correctly, the microtensile test shows more homogeneous distribution of stress, and thereby more sensitive comparison or evaluation of bond performances [22]. However, minute deviations in specimen alignment in the jig may cause increase bond strength due to shear component being introduced during debonding the adhered joints [23].

During chewing function since adhesive joints are exposed to both shear and tensile forces, information on adhesion durability with both tests remains crucial when ranking the performance of silane-cement combinations. When one to one comparisons were made for each silane-cement combination, the test method did not show significant difference in mean bond strength results for both dry and aged conditions. One explanation for this finding could be the similar surface area of the bonded areas in both tests. The results obtained correspond to the ranges summarized in a recent metaanalysis with similar cements [10]. Especially with the MDP based cement (PN), higher results were reported using the macrotensile test even in prolonged aged conditions $[8,8]$. However, it has to be noted that in those studies, cements were additionally polymerized in an oven under heat that was not practiced in this study as heat polymerization is neither manufacturer's recommendation nor clinically relevant. Nevertheless, the results achieved are still much inferior than those reported for glassy matrix ceramics after etching with hydrofluoric acid and silanization $[4,5]$. 
In this study, one methacrylate, one MDP based and self-adhesive cement was used where the latter does not require conditioning the dentin or ceramic surfaces. Such cements contain multifunctional phosphoric acid dimethacrylate modified monomers in their chemical compositions [17]. As zirconia ceramic includes oxides, in principle, the surface conditioning with primers or resins having adhesive functional monomers such as phosphoric acid group monomer in their composition are expected to improve the bonding to zirconia. With MSB and MTB test methods, after aging conditions, drastic decrease was observed in bond strength of self-adhesive cement tested. Likewise, the incidence of adhesive failures with this cement was also very high. Thus, it cannot be stated that bifunctional monomers of self-adhesive cement was sufficient to establish durable bond solely with this cement on zirconia. Without any surface conditioning and silanization, long-term stability of self-adhesive cement tested (RX) could not be expected [10]. Similarly, without the use of any primer/silane, methacrylate based cement VL resulted in practically no bond strength already in dry conditions. On the contrary some level of bonding could be achieved with MDP containing cement without the use of any primer/silane but these results increased significantly when zirconia surface was treated with an MDP containing primer. In both test methods, supported also by favourable Weilbul moduli in PN-AP groups clearly indicate possible copolymerization between AP primer and the PN cement. Although the results were not as favourable as for AP-PN, with the MP-VL combination also increased results were obtained. MP silane containing both MPS and MDP possibly co-polymerized on one side to zirconia with its MDP content, and on the other side to the mechacrylate resin cement with the MPS silane $[7,14,15]$. Yet, the results were not as favourable as AP-PN combination when bond strength, failure types and Weilbul moduli are considered. 
Hence, it could be stated that the compatibility of the primer/silane with the resin cement is decisive in durable adhesion to zirconia.

The poly-condensation of bifunctional silane monomer with the general formula of (RO-) 3-Si-O-R, R being the first and O-R the second silane functionality, can provide a highly cross-linked and reactive poly-organosiloxane layer on ceramics, also increasing the surface wettability [14]. Since they are prone to hydrolytic degradation $[14,21,22]$, attempts are being made to increase their cross-linking using other silanes [20] that could be further investigated after contamination. Nevertheless, hydrolysis of silane in water diminishes lifetime of adhesive joints [14,21,22]. When water molecules penetrate into the adhesive interface, existing physical bonds are destroyed and from the untreated surfaces cracks may initiate yielding to detachment of the resin-based materials $[14,21,22]$. In this regard, solvent evaporation represents a factor affecting the coupling potential of silanes [25]. Even though a small amount of solvent may help silane wetting, incomplete evaporation may impair adhesion. Water, alcohol, acetone, acetic acid and other by-products that remain on the surface, if not completely expelled by drying procedure, may remain as hydrogen-bonded to the $\mathrm{OH}$-rich sites. This may decrease the number of bond sites available for reacting with silane, thus compromising the final degree of siloxane bond formation [25]. Accordingly, heat treatment process was suggested to evaporate the solvent and volatile by-products from the silane reaction, catalyzing and completing the condensation reactions both with the substrate and within the silane coating [25]. In this study, no heat treatment was applied to the silane layer in any of the groups except for SG which was required according to the manufacturer's recommendations. Interestingly however, although SG contains 10MDP, significant decrease was noted after aging with both cements using the two test 
methods. This could relate to the less amount of MDP (0-5\%) in the SG silane according to the manufacturer`s information. In order to minimize hydrolytic degradation effect, heat treatment on the other tested primers/silanes warrants further research.

Oral fluids are known to degragade ceramic-resin interfaces resulting in slow crack growth [26]. Testing the adhesive joints either after water storage or thermocycling yield to hydrolytic degradation at the interface and usually results in decreased bond strength of resin-based materials to zirconia [7,27]. Exceptionally, in the control group with PN, after both test methods, increase in bond strength was noted. Also, in some other groups such as SG-PN and ES-R-PN similar observations were made. This could be attributed to further polymerization of $\mathrm{PN}$ cement at the $55^{\circ} \mathrm{C}$ during thermocycling. In future studies aging effect after long term water storage should be compared to thermocycling aging route.

One objective of this study was to find out whether application of primer/silanes alone could substirtute air-abrasion protocols where adhesion is achieved through micromechanical retention obtained with air-abrasion in part and the other as a consequence of chemical reaction with the the silane coupling agent. During airabrasion, since the energy available for crack propagation is in part dissipated in the damaged area shaped by the monoclinic zirconia, transformation toughening occurs in zirconia [28]. However, when the increase in volume exceeds the elastic limit of zirconia, it can promote the crack propagation, inducing new microcracks and even catastrophic fracture of the structure [29]. This mechanism could be influenced by several factors that act in an isolated or associated form, such as shape, size and location of grains, presence of defects and/or oxygen vacancies in the structure, type and amount of stabilizing oxides, manufacturing methods, applied stresses and 
temperature variation [30]. Based on the results obtained in air-abraded groups given the particle deposition parameters, could be substituted with some primer/silane-cement combinations. Particle deposition duration in this study was $15 \mathrm{~s}$ according to the manufacturer's instructions but prolonged duration longer than $20 \mathrm{~s}$ could increase the amount of silica particles on the surface also increasing the bonding sites for the silane [31]. Nonetheless, prolonged particle deposition or increased pressure could at the same time increase the monoclinical phase in zirconia $[18,19]$.

Bond strength data should also be interpreted with failure types. While Score 1 represents the adhesive and therefore weak bond strength, Scores 2 and 3 indicate better adhesion to the substrate. The high incidence of mixed failures (Scores 2 and 3) supports the statement that PN cement bond better to zirconia than with VL. Interestingly, both cements showed higher incidence of mixed failures after MTB test than with MSB. By this type of failure type, the cohesive strength of the resin cement also plays a role and when the cohesive strength does not exceed that of the adhesive strength at the bonded interface, the cement fails cohesively itself. Thus, future studies should also consider cement composition when interpreting failure types especially in tensile test methods.

Recently, some chemical etching solutions such as $\mathrm{CH}_{2} \mathrm{CL}_{2}$ and those containing ferric chloride has been reported to dissolve the grain structure on the zirconia surface, enlarging the grain boundaries throughout the preferential removal of the less-arranged, high-energy peripheral atoms [32]. The results of this study, should be also compared with non-invasive etching protocols on zirconia. 


\section{Conclusions}

From this study, the following could be concluded:

(1) Both 10-MDP and methacrylate cements tested profitted from the use of primers/silane coupling agents for improved adhesion to zirconia.

(2) Testing adhesion without aging through thermocycling did not result in significant difference between methacrylate and 10-MDP cement-silane combinations.

(3) After aging, 10-MDP cement with all silane combinations and methacrylate cement with AP and MP silanes showed significantly higher results compared to those of other silanes.

(4) In all tests and silane-cement combinations, bond strength results decreased the most with SG silane.

(5) After aging, Weilbul distribution indicated more reliable adhesion with AP-PN.

(6) Regardless of the test methods, after aging, cohesive failures in the cement were more commonly observed with 10-MDP cement compared to methacrylate or selfadhesive cements.

\section{Clinical Relevance}

Considering bond strength values and the failure types, regardless of test method, 10MDP based dual polymerized resin cement could be suggested as the choice of cement in conjunction with 10-MDP primer for more reliable adhesion to zirconia that could also as an alternative to air-abrasion protocols. 


\section{Acknowledgement}

We would like to acknowledge the manufacturing companies for generous provision of resin cements, primers and silane coupling agents used in this study and Mr. A. Trottmann for his assistance during the experimental procedures.

\section{Conflict of interest}

The authors did not have any commercial interest in any of the materials used in this study. 


\section{References}

[1] Guazzato M, Albakry M, Ringer SP, et al. Strength, fracture toughness and microstructure of a selection of all-ceramic materials. Part II. Zirconia-based dental ceramics. Dent. Mater. 2004;20:449-456.

[2] Larsson C, Wennerberg A. The clinical success of zirconia-based crowns: A systematic review. Int. J. Prosthodont. 2014;27:33-43.

[3] Edelhoff D, Özcan M. To what extent does the longevity of fixed dental prostheses depend on the function of the cement? Working Group 4 materials: cementation. Clin. Oral Implants Res. 2007;18:193-204.

[4] Özcan M, Vallittu PK. Effect of surface conditioning methods on the bond strength of luting cements to ceramics. Dent. Mater. 2003;19:725-731.

[5] Spohr AM, Sobrinho LC, Sinhoreti MA, et al. Influence of surface conditions and silane agent on the bond of resin to IPS Empress 2 ceramic. Int. J. Prosthodont. 2003;16:277-282.

[6] Özcan M, Kerkdijk S, Valandro LF. Comparison of resin cement adhesion to Y-TZP ceramic following manufacturers' instructions of the cements only. Clin. Oral Investig. $2008 ; 12: 279-282$.

[7] Özcan M, Nijhuis H, Valandro LF. Effect of various surface conditioning methods on the adhesion of dual-cure resin cement with MDP functional monomer to zirconia after thermal aging. Dent. Mater. J. 2008;27:99-104.

[8] Kern M, Barloi A, Yang B. Surface conditioning influences zirconia ceramic bonding. J. Dent. Res. 2009;88:817-822. 
[9] Yang B, Barloi A, Kern M. Influence of air-abrasion on zirconia ceramic bonding using an adhesive composite resin. Dent. Mater. 2010;26:44-50.

[10] Özcan M, Bernasconi M.Adhesion to zirconia used for dental restorations: a systematic review and meta-analysis. J. Adhes. Dent. 2015;17:7-26.

[11] Kern M. Resin bonding to oxide ceramics for dental restorations. J. Adhes. Sci. Tech. 2009;23:1097-1111.

[12] Zhang Y, Lawn BR, Rekow ED, et al. Effect of sandblasting on the long-term performance of dental ceramics. J. Biomed. Mater. Res. B Appl. Biomater. 2004;71:381386.

[13] Zhang Y, Lawn BR, Malament KA, et al. Damage accumulation and fatigue life of particle-abraded ceramics. Int. J. Prosthodont. 2006;19:442-448.

[14] Matinlinna JP, Lassila LV, Özcan M, et al. An introduction to silanes and their clinical applications in dentistry. Int. J. Prosthodont. 2004;17:155-164.

[15]Matinlinna JP, Heikkinen T, Özcan M, et al. Evaluation of resin adhesion to zirconia ceramic using some organosilanes. Dent. Mater. 2006;22:824-831.

[16] Magne P, Paranhos MP, Burnett LH. New zirconia primer improves bond strength of resin-based cements. Dent. Mater. 2010;26:345-352.

[17] Ferracane JL, Stansbury JW, Burke FJ. Self-adhesive resin cements - chemistry, properties and clinical considerations. J. Oral Rehabil. 2011;38:295-314.

[18] Özcan M, Melo RM, Souza RO, et al. Effect of air-particle abrasion protocols on the biaxial flexural strength, surface characteristics and phase transformation of zirconia after cyclic loading. J. Mech. Behav. Biomed. Mater. 2013;20:19-28.

[19] Souza RO, Valandro LF, Melo RM, et al. Air-particle abrasion on zirconia ceramic using different protocols: effects on biaxial flexural strength after cyclic loading, phase 
transformation and surface topography. J. Mech. Behav. Biomed. Mater. 2013;26:155163.

[20] Matinlinna J, Özcan M, Lassila L, et al. Effect of the cross-linking silane concentration in a novel silane system on bonding resin-composite cement. Acta Odontol. Scand. 2008;66:250-255.

[21] Ishida H, Koenig JL. Effect of hydrolysis and drying on the siloxane bonds of a silane coupling agent deposited on E-glass fibers. J. Polym. Sci. B: Polym. Phys. 1980;18:233-237.

[22] Barghi N. To silanate or not to silanate: making a clinical decision. Compend. Cont. Educ. Dent. 2000;21:659-662.

[23] Della Bona A, Van Noort R. Shear vs. tensile bond strength of resin composite bonded to ceramic. J. Dent. Res. 1995;74:1591-1596.

[24] Betamar N, Cardew G, Van Noort R. Influence of specimen designs on the microtensile bond strength to dentin. J. Adhes. Dent. 2007;9:159-168.

[25] Queiroz JR, Benetti P, Özcan M, et al. Surface characterization of feldspathic ceramic using ATR FT-IR and ellipsometry after various silanization protocols. Dent. Mater. 2012;28:189-196.

[26] Kohorst P, Dittmer MP, Borchers L, et al. Influence of cyclic fatigue in water on the load-bearing capacity of dental bridges made of zirconia. Acta Biomater. 2008;4:14401447.

[27] May LG, Passos SP, Capelli DB, et al. Effect of silica coating combined to a MDPbased primer on the resin bond to Y-TZP ceramic. J. Biomed. Mater. Res. B Appl. Biomater. 2010;95:69-74. 
[28] Chevalier J, Deville S, Münch E, et al. Critical effect of cubic phase on aging in $3 \mathrm{~mol} \%$ yttria-stabilized zirconia ceramics for hip replacement prosthesis. Biomaterials. 2004;25:5539-5545.

[29] Kelly JR, Denry I. Stabilized zircônia as a structural ceramic: An overview. Dent. Mater. 2008;24:289-298.

[30] Uo M, Sjögren G, Sundh A, et al. Cytotoxicity and bonding property of dental ceramics. Dent. Mater. 2003;19:487-492.

[31] Özcan M, Raadschelders J, Vallittu P, et al. Effect of particle deposition parameters on silica coating of zirconia using a chairside air-abrasion device. J. Adhes. Dent. 2013;15:211-214.

[32] Javid AH, Hassani AH, Golshan G. Selective removal of heavy metals from ferric chloride caused by etching processes by using sulfide precipitation. J. Environment. Sci. Technol. 2004;20:35-45. 


\section{Captions to figures and tables:}

\section{Figures:}

Fig. 1 Allocation of experimental groups based on the primer/silane coupling agents, resin luting cements, aging and test methods.

Figs. 2a-d Bond strength change in percentage after thermocycling for a) VLMacroshear, b) PN-Macroshear, c) VL-Macrotensile, d) PN-Macrotensile groups.

\section{Tables:}

Table 1. The brands, abbreviations, manufacturers, chemical compositions and batch numbers of the materials used in this study.

Tables 2a-b. The mean a) macroshear and $\mathbf{b})$ macrotensile bond strength values ( $\mathrm{MPa} \pm$ standard deviations), Weibull parameters (shape and scale), distribution and frequency of failure types per experimental group analyzed after bond strength test: Score 0: Adhesive failure at ceramic-cement interface with no cement remnants left on the substrate, Score 1: $<1 / 3$ cement left adhered on the substrate, Score $2:>1 / 3$ cement left adhered on the substrate. The same superscript lowercase letters in the same column indicate no significant differences for cement-dry and uppercase letters for cement-thermocycle combinations $(p<0.05)$. For group descriptions see Table 1.

Tables 3a-c. Significant differences between mean shear bond strengths of a) VL, b) PN, c) VL versus PN cements in dry conditions based on the primers and silanes (Tukey's and 2-sided Dunnett-T post hoc tests, $\alpha=0.05$ ). For group descriptions see Table 1. 
Tables 4a-c. Significant differences between mean shear bond strengths of a) VL, b) PN, c) VL versus PN cements after thermocycling based on the primers and silanes (Tukey's and 2-sided Dunnett-T post hoc tests, $\alpha=0.05$ ). For group descriptions see Table 1. Tables 5a-c. Significant diffrences between mean tensile bond strengths of a) VL, b) PN, c) VL versus PN cements in dry conditions based on the primers and silanes (Tukey's and 2-sided Dunnett-T post hoc tests, $\alpha=0.05$ ). For group descriptions see Table 1.

Tables 6a-c. Significant differences between mean tensile bond strengths of a) VL, b) PN, c) VL versus PN cements after thermocycling based on the primers and silanes (Tukey's and 2-sided Dunnett-T post hoc tests, $\alpha=0.05$ ). For group descriptions see Table 1. 
Tables:

\begin{tabular}{|c|c|c|c|}
\hline Brand & Manufacturer & Chemical Composition & $\begin{array}{l}\text { Batch } \\
\text { number }\end{array}$ \\
\hline \multicolumn{4}{|l|}{$\begin{array}{l}\text { Primers/Silane } \\
\text { coupling agents }\end{array}$} \\
\hline $\begin{array}{l}\text { Signum Zirconia Bond } \\
I+I I(S G)\end{array}$ & $\begin{array}{l}\text { Heraeus Kulzer, } \\
\text { Hanau, } \\
\text { Germany }\end{array}$ & $\begin{array}{l}\text { Monomer: 10-Methacryl- } \\
\text { oxydecyldihydrogenphosphate 0-5\% } \\
\text { Solvent: Aceton (>90\%), ethanol } \\
(<1 \%)\end{array}$ & $\begin{array}{l}010062 \\
010657\end{array}$ \\
\hline $\begin{array}{l}\text { Clearfil SE Bond and } \\
\text { Clearfil Porcelain Bond } \\
\text { Activator }(C L)\end{array}$ & Kuraray, Tokyo, Japan & $\begin{array}{l}\text { Monomer: 3- } \\
\text { trimethoxysilylpropylmethacrylate } \\
(<5 \%) \\
\text { Solvent: Ethanol }(80-100 \%)\end{array}$ & $\begin{array}{l}\text { Primer: } \\
\text { 00943A } \\
\text { Bond: } \\
\text { 01397A }\end{array}$ \\
\hline Alloy Primer (AP) & Kuraray & $\begin{array}{l}\text { Monomer: 6-(4-Vinylbenzyl-N-propyl) } \\
\text { Amino-1,3,5-Triazin-2,4-Dithion, 10- } \\
\text { Methacryloyloxydecyl- } \\
\text { Dihydrogenphosphate } \\
\text { Solvent: Aceton }(>90 \%)\end{array}$ & 00359A \\
\hline Monobond Plus (MP) & $\begin{array}{l}\text { Ivoclar Vivadent, } \\
\text { Schaan, Liechtenstein }\end{array}$ & $\begin{array}{l}\text { Monomer: }<1.5 \% \text { Methacrylate, } \\
\text { Phosphoric acid ester } \\
\text { Solvent: Ethanol }(96 \%)\end{array}$ & M2 4811 \\
\hline ESPE-Sil (ES) & $\begin{array}{l}\text { 3M ESPE, St. Paul, } \\
\text { USA }\end{array}$ & $\begin{array}{l}\text { Monomer: Ethyl alcohol, } \\
\text { 3- } \\
\text { methacryloxypropyltrimethoxysilane } \\
\text { Solvent: }>90 \% \text { Ethanol }\end{array}$ & \\
\hline \multicolumn{4}{|l|}{ Resin luting cements } \\
\hline Variolink II (VL) & Ivoclar Vivadent & $\begin{array}{l}\text { bis-GMA, UDMA, TEGDMA, BPO, } \\
\text { camphorquionine, } \\
\text { barium glass, ytterbium trifluoride, } \\
\text { Ba-Al fluorosilicate glass, spheroid } \\
\text { mixed oxide } \\
\text { Particle size: } 0.04 \text { - } 3 \mu \mathrm{m} \text { (mean: } 0.7 \\
\mu \mathrm{m} \text { ), } \\
\text { Filler load (base: } 73.4 \text { wt\%) } \\
\text { Filler load (catalyst high viscosity: } \\
77.2 \text { wt } \% \text { ) }\end{array}$ & $\mathrm{J} 17818$ \\
\hline Panavia F2.0 (PN) & Kuraray & $\begin{array}{l}\text { Paste A: 10- Methacryloyloxydecyl } \\
\text { dihydrogen phosphate } \\
\text { Paste B: Hydrophobic aromatic } \\
\text { dimethacrylate, Hydrophilic aliphatic } \\
\text { methacrylate, Hydrophilic aliphatic } \\
\text { dimethacrylate silanated barium glass } \\
\text { filler (wt\%) }\end{array}$ & $\begin{array}{l}00443 \mathrm{~A} \\
00221 \mathrm{~B}\end{array}$ \\
\hline $\begin{array}{l}\text { RelyX Unicem Aplicap } \\
(\mathrm{RX})\end{array}$ & 3M ESPE & $\begin{array}{l}\text { Water (30-40\%), copolymer of acrylic } \\
\text { and itaconic acid (30-40\%), 2- } \\
\text { Hydroxyethyl methacrylate (25-35\%) }\end{array}$ & 38266 \\
\hline
\end{tabular}




\begin{tabular}{|llll|}
\hline Particle type & & & \\
\hline Rocatec $(\mathrm{R})$ & $3 \mathrm{M}$ ESPE & $\begin{array}{l}110 \mu \mathrm{m} \mathrm{Al}_{2} \mathrm{O}_{3} \text { particles (Rocatec-Pre) } \\
110 \mu \mathrm{m} \text { silica coated } \mathrm{Al}_{2} \mathrm{O}_{3} \text { particles }\end{array}$ & \\
& & $\begin{array}{l}11520 \\
\text { (Rocatec-Plus) }\end{array}$ & \\
& $3 \mathrm{M}$ ESPE & $\begin{array}{l}30 \mu \mathrm{m} \text { aluminum oxide particles } \\
\text { coated with silica }\end{array}$ & \\
\hline CoJet $(\mathrm{C})$ & & \\
& &
\end{tabular}

Table 1. The brands, abbreviations, manufacturers, chemical compositions and batch numbers of the materials used in this study. 


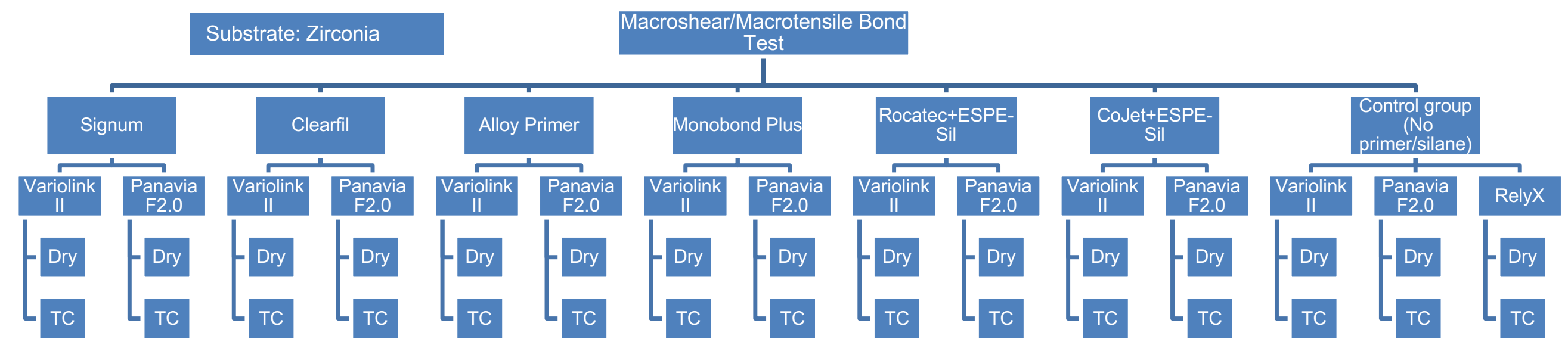

Fig. 1 Allocation of experimental groups based on the primer/silane coupling agents, resin luting cements, aging and test methods. 


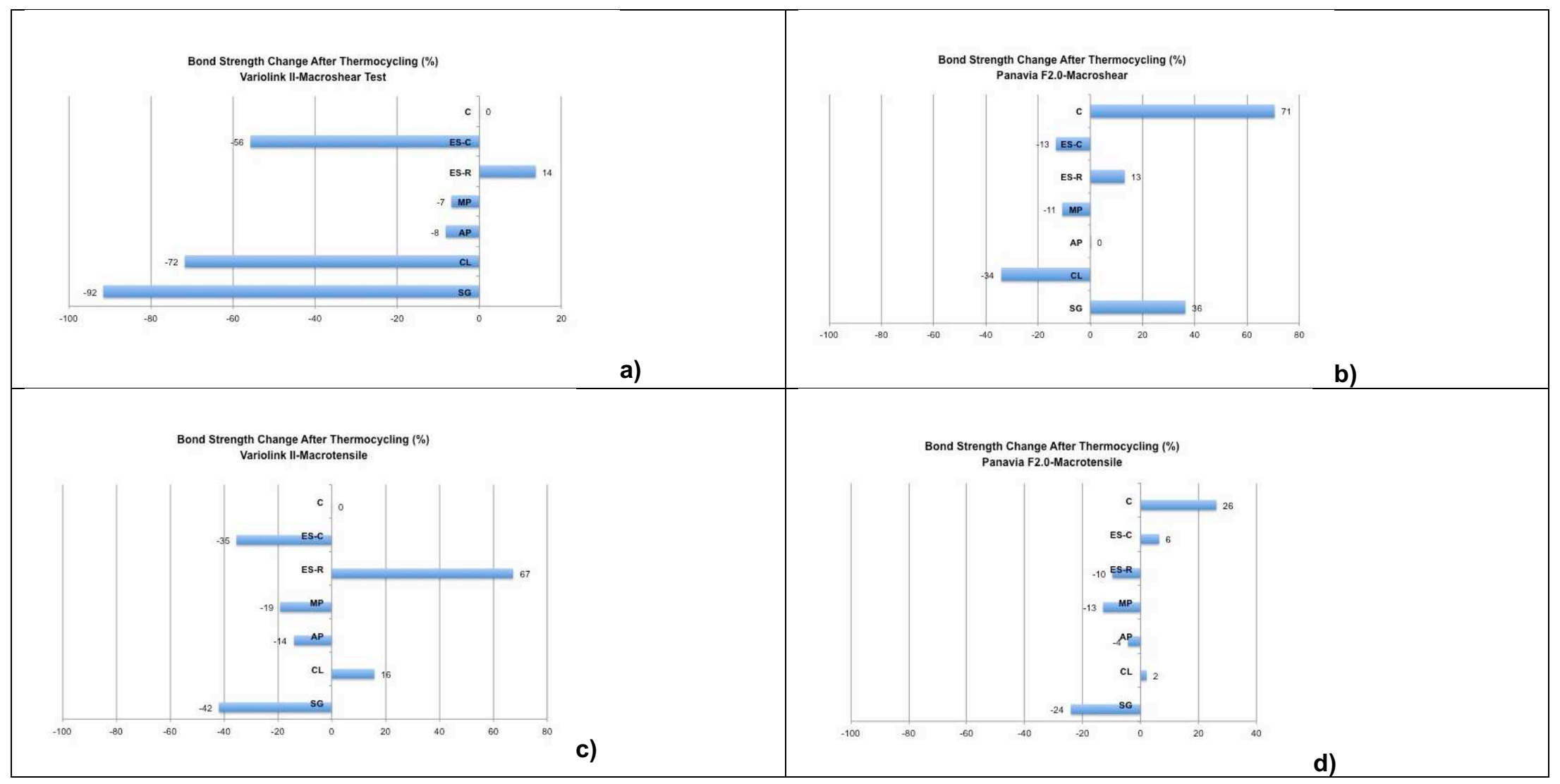

Figs. 2a-d Bond strength change in percentage after thermocycling for a) VL-Macroshear, b) PN-Macroshear, c) VLMacrotensile, d) PN-Macrotensile groups. 


\begin{tabular}{|c|c|c|c|c|c|c|c|c|c|}
\hline \multirow[b]{2}{*}{ Group } & \multirow[b]{2}{*}{$\begin{array}{c}\text { Primer/Silan } \\
\text { e }\end{array}$} & \multirow[b]{2}{*}{$\begin{array}{c}\text { Resin } \\
\text { Cement }\end{array}$} & \multirow[b]{2}{*}{ Aging } & \multirow[b]{2}{*}{$\begin{array}{l}\text { Macroshear bond } \\
\text { strength } \\
\text { (Mean } \pm \text { SD) }\end{array}$} & \multicolumn{2}{|c|}{ Weibull parameters } & \multicolumn{3}{|c|}{$\begin{array}{l}\text { Failure type distribution } \\
\qquad \mathrm{n}(\%)\end{array}$} \\
\hline & & & & & Shape & Scale & Score 0 & Score 1 & Score 2 \\
\hline 1 & SG & VL & Dry & $12 \pm 4.2^{\mathrm{a}}$ & 3.03 & 88.24 & $15(100)$ & $0(0)$ & $0(0)$ \\
\hline 2 & $\mathrm{CL}$ & VL & Dry & $15.4 \pm 6.2^{\mathrm{a}}$ & 2.76 & 114.50 & $15(100)$ & $0(0)$ & $0(0)$ \\
\hline 3 & AP & VL & Dry & $15 \pm 3.8^{a}$ & 3.2 & 87.27 & $15(100)$ & $0(0)$ & $0(0)$ \\
\hline 4 & MP & VL & Dry & $11.9 \pm 3.7^{\mathrm{a}}$ & 4.2 & 108.58 & $15(100)$ & $0(0)$ & $0(0)$ \\
\hline 5 & ES-R & VL & Dry & $8 \pm 3.9^{a}$ & 2.26 & 59.55 & $13(87)$ & $2(13)$ & $0(0)$ \\
\hline 6 & ES-C & VL & Dry & $12.3 \pm 5.2^{\mathrm{a}}$ & 2.59 & 91.51 & $14(93)$ & $1(7)$ & $0(0)$ \\
\hline 7 & SG & PN & Dry & $10.3 \pm 4.8^{\mathrm{a}}$ & 2.5 & 76.91 & $15(100)$ & $0(0)$ & $0(0)$ \\
\hline 8 & $\mathrm{CL}$ & $\mathrm{PN}$ & Dry & $14.1 \pm 2.9^{\mathrm{a}}$ & 5.26 & 100.69 & $3(21)$ & $12(79)$ & $0(0)$ \\
\hline 9 & AP & PN & Dry & $10.2 \pm 1.9^{a}$ & 6 & 72.54 & $5(35)$ & $10(55)$ & $0(0)$ \\
\hline 10 & MP & PN & Dry & $10.6 \pm 3.9^{a}$ & 3.66 & 77.96 & $3(21)$ & $12(79)$ & $0(0)$ \\
\hline 11 & ES-R & PN & Dry & $12.5 \pm 4^{a}$ & 3.46 & 91.9 & 11(72) & $3(21)$ & $1(7)$ \\
\hline 12 & ES-C & PN & Dry & $13.3 \pm 3.1^{\mathrm{a}}$ & 4.98 & 95.34 & $15(100)$ & $0(0)$ & $0(0)$ \\
\hline 13 & $\mathrm{C}$ & VL & Dry & $0^{\mathrm{b}}$ & 1.93 & 55.71 & $15(100)$ & $0(0)$ & $0(0)$ \\
\hline 14 & C & PN & Dry & $5.7 \pm 1.7^{\mathrm{a}, \mathrm{b}}$ & 3.89 & 41.69 & $15(100)$ & $0(0)$ & $0(0)$ \\
\hline 15 & $\mathrm{C}$ & $\mathrm{RX}$ & Dry & $12.1 \pm 5.2^{\mathrm{a}}$ & 2.55 & 90.40 & $15(100)$ & $0(0)$ & $0(0)$ \\
\hline 16 & SG & VL & TC & $1 \pm 0.4^{\mathrm{A}}$ & 1.07 & 2.2093 & $15(100)$ & $0(0)$ & $0(0)$ \\
\hline 17 & $\mathrm{CL}$ & VL & $\mathrm{TC}$ & $4.4 \pm 1.7^{\mathrm{A}}$ & 2.67 & 32.312 & $5(35)$ & $10(65)$ & $0(0)$ \\
\hline 18 & AP & $\mathrm{VL}$ & $\mathrm{TC}$ & $11.1 \pm 6.1^{B}$ & 2.04 & 100.04 & $15(100)$ & $0(0)$ & $0(0)$ \\
\hline 19 & MP & VL & TC & $13.8 \pm 3.7^{\mathrm{B}}$ & 4.2 & 83.34 & $15(100)$ & $0(0)$ & $0(0)$ \\
\hline
\end{tabular}




\begin{tabular}{|c|c|c|c|c|c|c|c|c|c|}
\hline 20 & ES-R & VL & $\mathrm{TC}$ & $9 \pm 5.5^{\mathrm{B}}$ & 1.8 & 67.43 & $15(100)$ & $0(0)$ & $0(0)$ \\
\hline 21 & ES-C & $\mathrm{VL}$ & $\mathrm{TC}$ & $5.4 \pm 3.3^{B}$ & 1.86 & 40.59 & $15(100)$ & $0(0)$ & $0(0)$ \\
\hline 22 & SG & PN & $\mathrm{TC}$ & $14 \pm 4.9^{A}$ & 3.2 & 103.22 & $8(51)$ & $7(49)$ & $0(0)$ \\
\hline 23 & CL & PN & $\mathrm{TC}$ & $9.2 \pm 4.9^{A}$ & 2.11 & 69.55 & $12(79)$ & $3(21)$ & $0(0)$ \\
\hline 24 & AP & PN & TC & $10.2 \pm 2.2^{\mathrm{A}}$ & 5.66 & 72.94 & $11(72)$ & $3(21)$ & 1(7) \\
\hline 25 & MP & PN & TC & $9.5 \pm 2.3^{\mathrm{A}}$ & 4.8 & 68.45 & $7(49)$ & $8(51)$ & $0(0)$ \\
\hline 26 & ES-R & PN & $\mathrm{TC}$ & $14.2 \pm 4.5^{\mathrm{A}}$ & 3.76 & 103.79 & $13(86)$ & $2(14)$ & $0(0)$ \\
\hline 27 & ES-C & PN & $\mathrm{TC}$ & $11.5 \pm 3.8^{A}$ & 3.32 & 84.58 & $13(86)$ & $2(14)$ & $0(0)$ \\
\hline 28 & C & $\mathrm{VL}$ & $\mathrm{TC}$ & $0^{\mathrm{B}}$ & 4.51 & 82.06 & $15(100)$ & $0(0)$ & $0(0)$ \\
\hline 29 & C & PN & $\mathrm{TC}$ & $9.7 \pm 3.4^{\mathrm{A}}$ & 3.06 & 71.81 & $7(49)$ & $8(51)$ & $0(0)$ \\
\hline 30 & $C$ & $\mathrm{RX}$ & TC & $6.3 \pm 4.3^{\mathrm{B}}$ & 0.6 & 13.18 & $15(100)$ & $0(0)$ & $0(0)$ \\
\hline
\end{tabular}

Table 2a. The mean macroshear bond strength values (MPa \pm standard deviations), Weibull parameters (shape and scale), distribution and frequency of failure types per experimental group analyzed after bond strength test: Score 0: Adhesive failure at ceramic-cement interface with no cement remnants left on the substrate, Score 1: $<1 / 3$ cement left adhered on the substrate, Score $2:>1 / 3$ cement left adhered on the substrate. The same superscript lowercase letters in the same column indicate no significant differences for cement-dry and uppercase letters for cement-thermocycle combinations $(p<0.05)$. For group descriptions see Table 1. 


\begin{tabular}{|c|c|c|c|c|c|c|c|c|c|}
\hline \multirow[b]{2}{*}{ Group } & \multirow[b]{2}{*}{ Primer/Silane } & \multirow[b]{2}{*}{ Resin Cement } & \multirow[b]{2}{*}{ Aging } & \multirow[b]{2}{*}{$\begin{array}{l}\text { Macrotensile bond } \\
\text { strength } \\
\text { (Mean } \pm \text { SD) }\end{array}$} & \multicolumn{2}{|c|}{ Weibull parameters } & \multicolumn{3}{|c|}{$\begin{array}{l}\text { Failure type distribution } \\
\qquad \mathrm{n}(\%)\end{array}$} \\
\hline & & & & & Shape & Scale & Score 0 & $\begin{array}{c}\text { Score } \\
1\end{array}$ & $\begin{array}{c}\text { Score } \\
2\end{array}$ \\
\hline 1 & SG & VL & Dry & $10.3 \pm 6.5^{\mathrm{a}}$ & 0.99 & 59.19 & $15(100)$ & $0(0)$ & $0(0)$ \\
\hline 2 & $\mathrm{CL}$ & VL & Dry & $13.8 \pm 4.1^{\mathrm{a}}$ & 3.93 & 100.46 & $0(0)$ & $0(0)$ & $\begin{array}{c}15 \\
(100)\end{array}$ \\
\hline 4 & MP & VL & Dry & $19.6 \pm 4.7^{b}$ & 4.53 & 141.74 & $1(7)$ & $0(0)$ & $14(93)$ \\
\hline 5 & ES-R & VL & Dry & $7.1 \pm 3.6^{a}$ & 0.76 & 27.66 & $15(100)$ & $0(0)$ & $0(0)$ \\
\hline 6 & ES-C & VL & Dry & $10.5 \pm 4.8^{\mathrm{a}}$ & 1.29 & 63.37 & $15(100)$ & $0(0)$ & $0(0)$ \\
\hline 7 & SG & PN & Dry & $4.4 \pm 3.8^{a}$ & 0.7 & 13.855 & $15(100)$ & $0(0)$ & $0(0)$ \\
\hline 8 & $\mathrm{CL}$ & PN & Dry & $12.8 \pm 4^{b}$ & 2.09 & 85.53 & $0(0)$ & $0(0)$ & $\begin{array}{c}15 \\
(100)\end{array}$ \\
\hline 9 & $\mathrm{AP}$ & PN & Dry & $13.3 \pm 1.6^{b}$ & 2.96 & 86.94 & $0(0)$ & $0(0)$ & $\begin{array}{c}15 \\
(100)\end{array}$ \\
\hline 10 & MP & PN & Dry & $13 \pm 3.7^{b}$ & 3.89 & 94.61 & $0(0)$ & $0(0)$ & $\begin{array}{c}15 \\
(100)\end{array}$ \\
\hline 11 & ES-R & PN & Dry & $12.7 \pm 2.9^{b}$ & 5.59 & 95.27 & $0(0)$ & $0(0)$ & $\begin{array}{c}15 \\
(100)\end{array}$ \\
\hline 12 & ES-C & PN & Dry & $12.1 \pm 2.3^{b}$ & 2.7 & 79.91 & $0(0)$ & $0(0)$ & $\begin{array}{c}15 \\
(100)\end{array}$ \\
\hline
\end{tabular}




\begin{tabular}{|c|c|c|c|c|c|c|c|c|c|}
\hline 13 & $\mathrm{C}$ & $\mathrm{VL}$ & Dry & $0^{a}$ & 3.39 & 93.39 & $15(100)$ & $0(0)$ & $0(0)$ \\
\hline 14 & $\mathrm{C}$ & PN & Dry & $7.2 \pm 2.7^{\mathrm{a}}$ & 2.89 & 52.55 & $14(93)$ & 1 (7) & $0(0)$ \\
\hline 15 & C & RX & Dry & $12.5 \pm 3.6^{b}$ & 3.89 & 91.11 & $11(93)$ & $4(28)$ & $0(0)$ \\
\hline 16 & SG & $\mathrm{VL}$ & TC & $6 \pm 5^{A}$ & 0.68 & 9.237 & $13(86)$ & $2(14)$ & $0(0)$ \\
\hline 17 & $\overline{C L}$ & $\mathrm{VL}$ & $\mathrm{TC}$ & $15.9 \pm 4.4^{B}$ & 2.56 & 94.81 & $0(0)$ & $0(0)$ & $\begin{array}{c}15 \\
(100)\end{array}$ \\
\hline 18 & AP & $\mathrm{VL}$ & TC & $13.5 \pm 3.7^{B}$ & 2.02 & 76.21 & $0(0)$ & $0(0)$ & $\begin{array}{c}15 \\
(100)\end{array}$ \\
\hline 19 & MP & $\mathrm{VL}$ & $\mathrm{TC}$ & $15.9 \pm 3.3^{B}$ & 4.04 & 84.23 & $0(0)$ & $0(0)$ & $\begin{array}{c}15 \\
(100)\end{array}$ \\
\hline 20 & ES-R & $\mathrm{VL}$ & TC & $11.5 \pm 4^{\mathrm{B}}$ & 1.56 & 73.23 & $0(0)$ & $0(0)$ & $15(100)$ \\
\hline 21 & ES-C & $\mathrm{VL}$ & $\mathrm{TC}$ & $6.8 \pm 3^{A}$ & 5.25 & 92.22 & $15(100)$ & $0(0)$ & $0(0)$ \\
\hline 22 & SG & PN & $\mathrm{TC}$ & $3.3 \pm 2.5^{\mathrm{A}}$ & 0.52 & 14.639 & $15(100)$ & $0(0)$ & $0(0)$ \\
\hline 23 & $\mathrm{CL}$ & PN & TC & $13 \pm 3.7^{B}$ & 0.55 & 5.691 & $0(0)$ & $0(0)$ & $15(100)$ \\
\hline 24 & AP & PN & $\mathrm{TC}$ & $12.7 \pm 2.6^{\mathrm{B}}$ & 5.41 & 113.58 & $1(7)$ & $0(0)$ & $14(93)$ \\
\hline 25 & MP & PN & TC & $11.3 \pm 3.9^{\mathrm{B}}$ & 3.6 & 115.97 & $1(7)$ & $0(0)$ & $14(93)$ \\
\hline 26 & ES-R & PN & TC & $12 \pm 2.5^{\mathrm{B}}$ & 4.79 & 97.89 & $1(7)$ & $0(0)$ & $14(93)$ \\
\hline 27 & ES-C & PN & TC & $12.9 \pm 3.4^{\mathrm{B}}$ & 3.38 & 84.76 & $0(0)$ & $0(0)$ & 15 (100) \\
\hline 28 & C & $\mathrm{VL}$ & $\mathrm{TC}$ & $0^{A}$ & * & * & $15(100)$ & $0(0)$ & $0(0)$ \\
\hline 29 & $\mathrm{C}$ & PN & TC & $9.7 \pm 3.2^{A}$ & 0.64 & 17.72 & $12(79)$ & $2(14)$ & $1(7)$ \\
\hline
\end{tabular}


Table 2b. The mean macrotensile bond strength values (MPa \pm standard deviations), Weibull parameters (shape and scale), distribution and frequency of failure types per experimental group analyzed after bond strength test: Score 0: Adhesive failure at ceramic-cement interface with no cement remnants left on the substrate, Score $1:<1 / 3$ cement left adhered on the substrate, Score $2:>1 / 3$ cement left adhered on the substrate. The same superscript lowercase letters in the same column indicate no significant differences for cement-dry and uppercase letters for cement-thermocycle combinations $(p<0.05)$. For group descriptions see Table 1. 


\begin{tabular}{|l|l|l|l|l|l|l|l|l|}
\hline$V L$ & SG & CL & AP & MP & ES-R & ES-C & C & RX \\
\hline SG & - & 0.540 & 1.000 & 0.734 & 0.268 & 1.000 & $0.000^{*}$ & 1.000 \\
\hline CL & 0.540 & - & 0.518 & 1.000 & $0.000^{*}$ & 0.717 & $0.000^{*}$ & 0.621 \\
\hline AP & 1.000 & 0.518 & - & 0.713 & 0.285 & 1.000 & $0.000^{*}$ & 1.000 \\
\hline MP & 0.734 & 1.000 & 0.713 & - & $0.000^{*}$ & 0.872 & $0.000^{*}$ & 0.801 \\
\hline ES-R & 0.268 & $0.000^{*}$ & 0.285 & $0.000^{*}$ & - & 0.154 & $0.000^{*}$ & 0.212 \\
\hline ES-C & 1.000 & 0.717 & 1.000 & 0.872 & 0.154 & - & $0.000^{*}$ & 1.000 \\
\hline C & $0.000^{*}$ & $0.000^{*}$ & $0.000^{*}$ & $0.000^{*}$ & $0.000^{*}$ & $0.000^{*}$ & - & $0.000^{*}$ \\
\hline
\end{tabular}

Table 3a. Significant differences between mean shear bond strengths of VL cement in dry conditions based on the primers and silanes (Tukey's and 2-sided Dunnett-T post hoc tests, $\alpha=0.05$ ). For group descriptions see Table 1.

\begin{tabular}{|l|l|l|l|l|l|l|l|l|}
\hline PN & SG & CL & AP & MP & ES-R & ES-C & C & RX \\
\hline SG & - & 0.054 & 0.085 & 0.290 & 1.000 & 0.893 & 0.131 & $0.000^{*}$ \\
\hline CL & 0.054 & - & 1.000 & 1.000 & $0.041^{*}$ & 0.957 & 1.000 & $0.001^{*}$ \\
\hline AP & 0.085 & 1.000 & - & 1.000 & 0.066 & 0.983 & 1.000 & $0.000^{*}$ \\
\hline MP & 0.290 & 1.000 & 1.000 & - & 0.240 & 1.000 & 1.000 & $0.000^{*}$ \\
\hline ES-R & 1.000 & $0.041^{*}$ & 0.066 & 0.240 & - & 0.852 & 0.104 & $0.000^{*}$ \\
\hline ES-C & 0.893 & 0.957 & 0.983 & 1.000 & 0.852 & - & 0.994 & $0.000^{*}$ \\
\hline C & 0.131 & 1.000 & 1.000 & 1.000 & 0.104 & 0.994 & - & $0.000^{*}$ \\
\hline
\end{tabular}

Table 3b. Significant differences between mean shear bond strengths of PN cement in dry conditions based on the primers and silanes.

\begin{tabular}{|l|l|l|l|l|l|l|l|l|}
\hline$V L v s ~ P N$ & SG & CL & AP & MP & ES-R & ES-C & C & RX \\
\hline SG & 0.950 & $0.007^{*}$ & 0.957 & $0.019^{*}$ & 0.998 & 0.862 & $0.000^{*}$ & 0.918 \\
\hline CL & 0.980 & 1.000 & 0.976 & 1.000 & $0.003^{*}$ & 0.997 & $0.000^{*}$ & 0.990 \\
\hline AP & 1.000 & $0.078^{*}$ & 1.000 & 0.157 & 0.868 & 0.998 & $0.000^{*}$ & 0.999 \\
\hline MP & 0.997 & $0.031^{*}$ & 0.997 & $0.070^{*}$ & 0.965 & 0.980 & $0.000^{*}$ & 0.992 \\
\hline ES-R & 1.000 & 0.806 & 1.000 & 0.927 & 0.108 & 1.000 & $0.000^{*}$ & 1.000 \\
\hline ES-C & 1.000 & 0.979 & 1.000 & 0.997 & $0.023^{*}$ & 1.000 & $0.000^{*}$ & 1.000 \\
\hline C & $0.002^{*}$ & $0.000^{*}$ & $0.002^{*}$ & $0.000^{*}$ & 0.966 & 0.001 & $0.009^{*}$ & $0.001^{*}$ \\
\hline
\end{tabular}

Table 3c. Cross-comparison of significant differences between mean shear bond strengths of of VL versus PN cement in dry conditions based on the primers and silanes. 


\begin{tabular}{|l|l|l|l|l|l|l|l|l|}
\hline$V L$ & SG & CL & AP & MP & ES-R & ES-C & C & RX \\
\hline SG & - & 0.175 & $0.000^{*}$ & $0.000^{*}$ & $0.000^{*}$ & $0.041^{*}$ & 1.000 & 0.821 \\
\hline CL & 0.175 & - & $0.000^{*}$ & $0.000^{*}$ & 0.062 & 1.000 & 0.122 & 1.000 \\
\hline AP & $0.000^{*}$ & $0.000^{*}$ & - & 0.848 & 0.978 & $0.002^{*}$ & $0.000^{*}$ & $0.000^{*}$ \\
\hline MP & $0.000^{*}$ & $0.000^{*}$ & 0.848 & - & 0.058 & $0.000^{*}$ & $0.000^{*}$ & $0.000^{*}$ \\
\hline ES-R & $0.000^{*}$ & 0.062 & 0.978 & 0.058 & - & 0.238 & $0.000^{*}$ & $0.002^{*}$ \\
\hline ES-C & $0.041^{*}$ & 1.000 & $0.002^{*}$ & $0.000^{*}$ & 0.238 & - & $0.026^{*}$ & 0.969 \\
\hline C & 1.000 & 0.122 & $0.000^{*}$ & $0.000^{*}$ & $0.000^{*}$ & $0.026^{*}$ & - & 0.732 \\
\hline
\end{tabular}

Table 4a. Significant differences between mean shear bond strengths of VL cement after thermocycling based on the primers and silanes (Tukey's and 2-sided Dunnett-T post hoc tests, $\alpha=0.05$ ). For group descriptions see Table 1.

\begin{tabular}{|l|l|l|l|l|l|l|l|l|}
\hline PN & SG & CL & AP & MP & ES-R & ES-C & C & RX \\
\hline SG & - & 0.128 & 1.000 & 1.000 & 0.787 & 0.423 & 0.310 & 0.918 \\
\hline CL & 0.128 & - & 0.534 & 0.323 & 0.999 & 1.000 & $0.000^{*}$ & 0.990 \\
\hline AP & 1.000 & 0.534 & - & 1.000 & 0.993 & 0.890 & 0.52 & 0.999 \\
\hline MP & 1.000 & 0.323 & 1.000 & - & 0.957 & 0.721 & 0.121 & 0.992 \\
\hline ES-R & 0.787 & 0.999 & 0.993 & 0.957 & - & 1.000 & $0.000^{*}$ & 1.000 \\
\hline ES-C & 0.423 & 1.000 & 0.890 & 0.721 & 1.000 & - & $0.000^{*}$ & 1.000 \\
\hline C & 0.310 & $0.000^{*}$ & 0.052 & 0.121 & $0.000^{*}$ & $0.000^{*}$ & - & $0.001^{*}$ \\
\hline
\end{tabular}

Table 4b. Significant differences between mean shear bond strengths of PN cement after thermocycling based on the primers and silanes.

\begin{tabular}{|l|l|l|l|l|l|l|l|l|}
\hline VL vs $P N$ & SG & CL & AP & MP & ES-R & ES-C & C & RX \\
\hline SG & $0.000^{*}$ & $0.000^{*}$ & 0.735 & 1.000 & $0.032^{*}$ & $0.000^{*}$ & $0.000^{*}$ & $0.000^{*}$ \\
\hline CL & $0.000^{*}$ & $0.037^{*}$ & 0.993 & 0.093 & 1.000 & 0.162 & $0.000^{*}$ & $0.001^{*}$ \\
\hline AP & $0.000^{*}$ & $0.022^{*}$ & 0.998 & 0.142 & 1.000 & 0.109 & $0.000^{*}$ & $0.000^{*}$ \\
\hline MP & $0.000^{*}$ & $0.004^{*}$ & 1.000 & 0.413 & 1.000 & $0.024^{*}$ & $0.000^{*}$ & $0.000^{*}$ \\
\hline ES-R & $0.000^{*}$ & $0.000^{*}$ & 0.673 & 1.000 & $0.024^{*}$ & $0.000^{*}$ & $0.000^{*}$ & $0.000^{*}$ \\
\hline ES-C & $0.000^{*}$ & $0.000^{*}$ & 1.000 & 0.954 & 0.909 & $0.001^{*}$ & $0.000^{*}$ & $0.000^{*}$ \\
\hline C & $0.000^{*}$ & $0.013^{*}$ & 1.000 & 0.209 & 1.000 & 0.069 & $0.000^{*}$ & $0.000^{*}$ \\
\hline
\end{tabular}

Table 4c. Cross-comparison of significant differences between mean shear bond strengths of of VL versus PN cement after thermocycling based on the primers and silanes. 


\begin{tabular}{|l|l|l|l|l|l|l|l|l|}
\hline$V L$ & SG & CL & AP & MP & ES-R & ES-C & C & RX \\
\hline SG & - & 0.138 & $0.000^{*}$ & $0.002^{*}$ & 0.306 & 1.000 & $0.000^{*}$ & 0.625 \\
\hline CL & 0.138 & - & $0.017^{*}$ & 0.996 & $0.000^{*}$ & 0.160 & $0.000^{*}$ & 1.000 \\
\hline AP & $0.000^{*}$ & $0.017^{*}$ & - & 0.431 & $0.000^{*}$ & $0.000^{*}$ & $0.000^{*}$ & $0.001^{*}$ \\
\hline MP & $0.002^{*}$ & 0.996 & 0.431 & - & $0.000^{*}$ & $0.003^{*}$ & $0.000^{*}$ & 0.762 \\
\hline ES-R & 0.306 & $0.000^{*}$ & $0.000^{*}$ & $0.000^{*}$ & - & 0.271 & 0.154 & $0.000^{*}$ \\
\hline ES-C & 1.000 & 0.160 & $0.000^{*}$ & $0.003^{*}$ & 0.271 & - & $0.000^{*}$ & 0.669 \\
\hline C & $0.000^{*}$ & $0.000^{*}$ & $0.000^{*}$ & $0.000^{*}$ & 0.154 & $0.000^{*}$ & - & $0.000^{*}$ \\
\hline
\end{tabular}

Table 5a. Significant diffrences between mean tensile bond strengths of VL cement in dry conditions based on the primers and silanes (Tukey's and 2-sided Dunnett-T post hoc tests, $\alpha=0.05$ ). For group descriptions see Table 1.

\begin{tabular}{|l|l|l|l|l|l|l|l|l|}
\hline$P N$ & SG & CL & AP & MP & ES-R & ES-C & C & RX \\
\hline SG & - & $0.000^{*}$ & $0.000^{*}$ & $0.000^{*}$ & $0.000^{*}$ & $0.000^{*}$ & 0.201 & 1.000 \\
\hline CL & $0.000^{*}$ & - & 1.000 & 1.000 & 1.000 & 1.000 & 0.150 & 1.000 \\
\hline AP & $0.000^{*}$ & 1.000 & - & 1.000 & 1.000 & 0.999 & $0.019^{*}$ & 1.000 \\
\hline MP & $0.000^{*}$ & 1.000 & 1.000 & - & 1.000 & 1.000 & 0.062 & 1.000 \\
\hline ES-R & $0.000^{*}$ & 1.000 & 1.000 & 1.000 & - & 0.994 & $0.010^{*}$ & 1.000 \\
\hline ES-C & $0.000^{*}$ & 1.000 & 0.999 & 1.000 & 0.994 & - & 0.339 & 1.000 \\
\hline C & 0.201 & 0.150 & $0.019^{*}$ & 0.062 & $0.010^{*}$ & 0.339 & - & 0.054 \\
\hline
\end{tabular}

Table 5b. Significant diffrences between mean tensile bond strengths of PN cement in dry conditions based on the primers and silanes.

\begin{tabular}{|l|l|l|l|l|l|l|l|l|}
\hline$V L$ vs $P N$ & SG & CL & AP & MP & ES-R & ES-C & C & RX \\
\hline SG & $0.006^{*}$ & $0.000^{*}$ & $0.000^{*}$ & $0.000^{*}$ & 0.990 & $0.005^{*}$ & 0.940 & $0.000^{*}$ \\
\hline CL & 0.859 & 0.997 & $0.000^{*}$ & 0.497 & $0.001^{*}$ & 0.887 & $0.000^{*}$ & 1.000 \\
\hline AP & 0.389 & 1.000 & $0.003^{*}$ & 0.922 & $0.000^{*}$ & 0.431 & $0.000^{*}$ & 1.000 \\
\hline MP & 0.659 & 1.000 & $0.001^{*}$ & 0.732 & $0.000^{*}$ & 0.702 & $0.000^{*}$ & 1.000 \\
\hline ES-R & 0.264 & 1.000 & $0.006^{*}$ & 0.971 & $0.000^{*}$ & 0.299 & $0.000^{*}$ & 1.000 \\
\hline ES-C & 0.974 & 0.965 & $0.000^{*}$ & 0.253 & $0.003^{*}$ & 0.982 & $0.000^{*}$ & 1.000 \\
\hline C & 0.998 & $0.003^{*}$ & $0.000^{*}$ & $0.000^{*}$ & 0.965 & 0.997 & $0.001^{*}$ & 0.054 \\
\hline
\end{tabular}

Table 5c. Cross-comparison of significant differences between mean tensile bond strengths of of VL versus PN cement in dry conditions based on the primers and silanes. 


\begin{tabular}{|l|l|l|l|l|l|l|l|l|}
\hline$V L$ & SG & CL & AP & MP & ES-R & ES-C & C & RX \\
\hline SG & - & $0.000^{*}$ & $0.000^{*}$ & $0.000^{*}$ & $0.000^{*}$ & 1.000 & 0.999 & 0.194 \\
\hline CL & $0.000^{*}$ & - & 1.000 & 0.953 & 0.174 & $0.000^{*}$ & $0.000^{*}$ & $0.000^{*}$ \\
\hline AP & $0.000^{*}$ & 1.000 & - & 0.961 & 0.189 & $0.000^{*}$ & $0.000^{*}$ & $0.000^{*}$ \\
\hline MP & $0.000^{*}$ & 0.953 & 0.961 & - & 0.990 & $0.000^{*}$ & $0.000^{*}$ & $0.000^{*}$ \\
\hline ES-R & $0.000^{*}$ & 0.174 & 0.189 & 0.990 & - & $0.000^{*}$ & $0.000^{*}$ & $0.024^{*}$ \\
\hline ES-C & 1.000 & $0.000^{*}$ & $0.000^{*}$ & $0.000^{*}$ & $0.000^{*}$ & - & 0.894 & 0.671 \\
\hline C & 0.999 & $0.000^{*}$ & $0.000^{*}$ & $0.000^{*}$ & $0.000^{*}$ & 0.894 & - & $0.008^{*}$ \\
\hline
\end{tabular}

Table 6a. Significant differences between mean tensile bond strengths of VL cement after thermocycling based on the primers and silanes (Tukey's and 2-sided Dunnett-T post hoc tests, $\alpha=0.05$ ). For group descriptions see Table 1.

\begin{tabular}{|l|l|l|l|l|l|l|l|l|}
\hline$P N$ & SG & CL & AP & MP & ES-R & ES-C & C & RX \\
\hline SG & - & $0.000^{*}$ & $0.000^{*}$ & $0.000^{*}$ & $0.000^{*}$ & $0.000^{*}$ & 0.986 & 0.246 \\
\hline CL & $0.000^{*}$ & - & 0.947 & 1.000 & 0.919 & 1.000 & $0.000^{*}$ & $0.000^{*}$ \\
\hline AP & $0.000^{*}$ & 0.947 & - & 1.000 & 1.000 & 0.967 & $0.001^{*}$ & 0.141 \\
\hline MP & $0.000^{*}$ & 1.000 & 1.000 & - & 1.000 & 1.000 & $0.000^{*}$ & $0.010^{*}$ \\
\hline ES-R & $0.000^{*}$ & 0.919 & 1.000 & 1.000 & - & 0.946 & $0.002^{*}$ & 0.178 \\
\hline ES-C & $0.000^{*}$ & 1.000 & 0.967 & 1.000 & 0.946 & - & $0.000^{*}$ & $0.001^{*}$ \\
\hline C & 0.986 & $0.000^{*}$ & $0.001^{*}$ & $0.000^{*}$ & $0.002^{*}$ & $0.000^{*}$ & - & 0.986 \\
\hline
\end{tabular}

Table 6b. Significant diffrences between mean tensile bond strengths of PN cement after thermocycling based on the primers and silanes.

\begin{tabular}{|l|l|l|l|l|l|l|l|l|}
\hline$V L$ vs $P N$ & SG & CL & AP & MP & ES-R & ES-C & C & RX \\
\hline SG & 1.000 & $0.000^{*}$ & $0.000^{*}$ & $0.000^{*}$ & $0.000^{*}$ & 1.000 & 0.998 & 0.246 \\
\hline CL & $0.000^{*}$ & 0.829 & 0.848 & 1.000 & 0.999 & $0.000^{*}$ & $0.000^{*}$ & $0.000^{*}$ \\
\hline AP & $0.000^{*}$ & $0.031^{*}$ & $0.035^{*}$ & 0.816 & 1.000 & $0.000^{*}$ & $0.000^{*}$ & 0.141 \\
\hline MP & $0.000^{*}$ & 0.308 & 0.330 & 0.999 & 1.000 & $0.000^{*}$ & $0.000^{*}$ & $0.010^{*}$ \\
\hline ES-R & $0.000^{*}$ & 0.023 & $0.026^{*}$ & 0.759 & 1.000 & $0.000^{*}$ & $0.000^{*}$ & 0.178 \\
\hline ES-C & $0.000^{*}$ & 0.776 & 0.798 & 1.000 & 1.000 & $0.000^{*}$ & $0.000^{*}$ & $0.001^{*}$ \\
\hline C & 0.973 & $0.000^{*}$ & $0.000^{*}$ & $0.000^{*}$ & $0.000^{*}$ & 1.000 & 0.386 & 0.986 \\
\hline
\end{tabular}

Table 6c. Cross-comparison of significant differences between mean tensile bond strengths of of VL versus PN cement after thermocycling based on the primers and silanes. 